\title{
Association between VDR gene Fokl polymorphism and renal function in patients with IgA nephropathy
}

\author{
Man-Qiu Mo ${ }^{\text {Equal first author, } 1}{ }^{1}$, Ling Pan ${ }^{\text {Equal first author, } 1}{ }^{1}$, Lin Tan ${ }^{1}$, Ling Jiang ${ }^{1}$, Yong-Qing Pan ${ }^{1}$, Fu-Ji Li ${ }^{1}$, Yun-Hua Liao ${ }^{\text {Corresp., }}$ \\ ${ }^{1}$, Zhen-Hua Yang ${ }^{\text {Corresp. } 1}$ \\ ${ }^{1}$ Department of Nephrology, the First Affiliated Hospital of Guangxi Medical University, Nanning, China \\ Corresponding Authors: Yun-Hua Liao, Zhen-Hua Yang \\ Email address: yunhualiao1962@163.com, 593456108@qq.com
}

Background . Studies have shown that the occurrence and development of IgA nephropathy (IgAN) are genetically susceptible, but the relationship between vitamin $D$ receptor $(V D R)$ gene polymorphisms and renal function in IgAN patients is unclear.

Methods. We investigated the relationship between VDR Fokl (rs2228570) single nucleotide polymorphism (SNP) and renal function and related clinicopathologic parameters in IgAN patients. Clinical and pathological data of 282 IgAN patients treated at the First Affiliated Hospital of Guangxi Medical University were collected, and Fokl genotypes were determined by PCR and direct sequencing. Patients were divided into the renal dysfunction group and normal renal function (control) group by estimated glomerular filtration rate (eGFR) and serum creatinine level. Results. Frequencies of $\Pi T$ genotype and T allele in the renal dysfunction group were higher than those of the control group. Blood urea nitrogen, serum phosphorus $(\mathrm{P})$, proportions of mesangial cell proliferation, interstitial fibrosis/tubular atrophy and crescents in T allele carriers were higher than those in non- $T$ allele carriers, while eGFR and 25-Dihydroxyvitamin D3 were lower in T allele carriers than non-T allele carriers. Multiple linear regression analysis showed that eGFR was affected by Fokl genotypes in IgAN patients. Logistics regression analysis showed that middle and elderly age, elevated $P$, intact parathyroid hormone and $\Pi$ genotype were independent risk factors for renal dysfunction in IgAN patients; the odds ratio of carrying the $\pi$ genotype was as high as 84.77 ( $\mathrm{P}<0.05$ for all). Conclusion s. IgAN patients carrying the VDR Fokl TT genotype have an increased risk of renal dysfunction. VDR FokI SNP is closely related to renal function, calcium-phosphate metabolism and related pathological damage in IgAN patients. 


\section{Association between VDR gene FokI polymorphism and renal function in}

2 patients with IgA nephropathy

3

4 Man-Qiu Mo*, Ling Pan*, Lin Tan, Ling Jiang, Yong-Qing Pan, Fu-Ji Li, Yun-Hua Liao**, 5 Zhen-Hua Yang**

6 Department of Nephrology, the First Affiliated Hospital of Guangxi Medical University,

$7 \quad$ Nanning 530021, China

8 *These authors contributed equally to this study.

$9 * *$ Corresponding authors: Yun-Hua Liao, Department of Nephrology, the First Affiliated 10 Hospital of Guangxi Medical University, Nanning 530021, China. Email:

11 yunhualiao1962@163.com; Zhen-Hua Yang, Department of Nephrology, the First Affiliated 12 Hospital of Guangxi Medical University, Nanning 530021, China. Email: 593456108@qq.com.

\section{Abstract}

Background. Studies have shown that the occurrence and development of IgA nephropathy (IgAN) are genetically susceptible, but the relationship between vitamin D receptor (VDR) gene polymorphisms and renal function in $\operatorname{IgAN}$ patients is unclear.

Methods. We investigated the relationship between VDR FokI (rs2228570) single nucleotide polymorphism (SNP) and renal function and related clinicopathologic parameters in IgAN patients. Clinical and pathological data of $282 \operatorname{IgAN}$ patients treated at the First Affiliated Hospital of Guangxi Medical University were collected, and FokI genotypes were determined by PCR and direct sequencing. Patients were divided into the renal dysfunction group and normal renal function (control) group by estimated glomerular filtration rate (eGFR) and serum creatinine level.

Results. Frequencies of TT genotype and T allele in the renal dysfunction group were higher than those of the control group. Blood urea nitrogen, serum phosphorus $(\mathrm{P})$, proportions of mesangial cell proliferation, interstitial fibrosis/tubular atrophy and crescents in $\mathrm{T}$ allele carriers were higher than those in non-T allele carriers, while eGFR and 25-Dihydroxyvitamin D3 were lower in T allele carriers than non-T allele carriers. Multiple linear regression analysis showed 
30

31

32

33

34

35

36

37

38

39

40

41

42

43

44

45

46

47

48

49

50

51

52

53

54

55

56

57

58

59 Materials \& Methods

that eGFR was affected by FokI genotypes in IgAN patients. Logistics regression analysis showed that middle and elderly age, elevated $\mathrm{P}$, intact parathyroid hormone and TT genotype were independent risk factors for renal dysfunction in IgAN patients; the odds ratio of carrying the TT genotype was as high as $84.77(\mathrm{P}<0.05$ for all $)$.

Conclusions. IgAN patients carrying the VDR FokI TT genotype have an increased risk of renal dysfunction. VDR FokI SNP is closely related to renal function, calcium-phosphate metabolism and related pathological damage in IgAN patients.

\section{Introduction}

As one of the most common primary glomerular diseases, IgA nephropathy (IgAN) results in a high incidence of renal dysfunction, and more than $40 \%$ of patients progress to end-stage renal disease (ESRD) within 20 years ( $\mathrm{Li}$ et al. 2015). Many studies have shown that genetic cause is one of the primary factors affecting IgAN (Magistroni et al. 2015). Recently, genome-wide association studies (GWAS) have identified 20 genetic susceptibility genes of IgAN, which are closely related to the occurrence, progression and prognosis of IgAN.

The vitamin D receptor $(V D R)$ gene is a crucial mediator of active vitamin D biological activity. Active vitamin D binds to VDR to regulate target gene transcription, thus realizing biological functions such as regulation of calcium-phosphorus metabolism, immunity and inflammatory state (Christensen et al. 2013). VDR polymorphisms are associated with occurrence and prognosis of certain diseases, such as chronic kidney disease (CKD), ischemic stroke and malignant tumors (Cho et al. 2018; Prabhakar et al. 2015; Santoro et al. 2013). FokI is one locus located in the initiation codon region of $V D R$, which is the only functional locus known to affect VDR protein peptide chain structure (Hu et al. 2017). Previous studies have indicated that FokI polymorphism was associated with diabetic nephropathy and lupus nephritis, which increased the susceptibility of chronic renal failure (CRF) (Imam et al. 2017; Razi et al. 2019). However, the relationship between $V D R$ polymorphisms and renal function of IgAN patients is unclear. Hence, we investigated the association between VDR FokI single nucleotide polymorphism (SNP) and renal function and related clinicopathological damage of IgAN. 


\section{Subjects}

61 All subjects were patients treated in the Department of Nephrology at the First Affiliated

62 Hospital of Guangxi Medical University from August 2014 to December 2016, who were

63 diagnosed with IgAN by renal biopsy. Inclusion criteria were patients who met diagnostic

64 criteria of the 2014 edition of the IgAN Guidelines issued by the Japanese Society of Nephrology

65 (Yuzawa et al. 2016) and age $\geq 16$ years. Exclusion criteria were secondary IgAN (secondary to

66 autoimmune diseases such as allergic purpura, systemic lupus erythematosus, dry syndrome,

67 arthritis and psoriasis or secondary to hepatobiliary and gastrointestinal diseases, respiratory

68 diseases, viral infections and tumors) (Saha et al. 2018), patients with severe liver failure,

69 patients with acute cardiovascular diseases or acute cerebrovascular diseases and patients with a

70 history of medications such as steroid hormones, immunosuppressants and active vitamin D

71 preparations/analogs for the past 3 months. The study was approved by the Ethics Committee of

72 the First Affiliated Hospital of Guangxi Medical University (Approval Number: 2019KY-E-006),

73 and all participants were aware of the purpose of this study and provided written informed

74 consent. Ultimately, 282 subjects were included in this study.

\section{Clinical data}

76 Basic information of subjects was collected by questionnaires. Height, weight and vital signs

77 were recorded. Body mass index $(\mathrm{BMI})$ was calculated by the following formula: $\mathrm{BMI}=$ weight

$78(\mathrm{~kg}) /$ height $^{2}\left(\mathrm{~m}^{2}\right)$. Pulse pressure was calculated by the following formula: pulse pressure $=$

79 systolic blood pressure (SBP) - diastolic blood pressure (DBP).

80 Peripheral venous blood (4 mL) was obtained from each participant and used to examine liver 81 and kidney function, electrolytes, iPTH, 25-Dihydroxyvitamin D3 [25(OH) 2 D3] and 25-

82 Dihydroxyvitamin D2 $\left[25(\mathrm{OH})_{2} \mathrm{D} 2\right]$. We also collected 24-hour urine volume for urine protein

83 quantitation. Morning urine samples (approximately $5 \mathrm{~mL}$ ) were used for routine urine testing.

\section{Clinical grouping}

85 eGFR was calculated using the Chronic Kidney Disease Epidemiology Collaboration equation 86 according to serum creatinine (Scr), sex and age (Levey et al. 2017). eGFR $<60 \mathrm{~mL} / \mathrm{min} / 1.73 \mathrm{~m}^{2}$

87 and/or Scr $>104 \mu \mathrm{mmol} / \mathrm{L}$ in males or Scr $>84 \mu \mathrm{mmol} / \mathrm{L}$ in females was considered to indicate 
88 renal dysfunction. Subjects were then divided into the renal dysfunction group $(n=156)$ and the

89 control group (normal renal function group, $\mathrm{n}=126$ ) for analyses.

90

91

92

93

94

95

96

97

98

99

100

101

102

103

104

105

106

107

108

109

110

111

112

113

114

115

116

117

\section{DNA amplification, sequencing and genotyping}

Genomic DNA was extracted from peripheral blood leukocytes using the phenol-chloroform method (Nan et al. 2016). Based on gene sequences provided by the National Center for Biotechnology, specific primers were devised and aligned by Primer 5.0 software (Premier Company, Canada). The primer pair rs2228570-3F: 5'-TGGGTGGCACCAAGGATG-3' and rs2228570-3R: 5'-CCTTCATGGAAACACCTTGC-3' was synthesized by Shanghai Sangon Biological Engineering Technology \& Services Co., Ltd., China. PCR was performed in 40- $\mu \mathrm{L}$ volume reactions comprising $20 \mu \mathrm{L}$ of master mix, $17 \mu \mathrm{L}$ of water, $1 \mu \mathrm{L}$ of each upstream and downstream primer and $1 \mu \mathrm{L}$ of DNA template. PCR cycle conditions were as follows: initial denaturing at $94^{\circ} \mathrm{C}$ for $5 \mathrm{~min}$, followed by 35 cycles of denaturing at $94^{\circ} \mathrm{C}$ for $30 \mathrm{~s}$, annealing at $55^{\circ} \mathrm{C}$ for $30 \mathrm{~s}$ and elongation at $72^{\circ} \mathrm{C}$ for $30 \mathrm{~s}$. Amplification was completed with a final extension at $72^{\circ} \mathrm{C}$ for $5 \mathrm{~min}$. PCR products were visualized on $2.0 \%$ agarose gels (Fig. 1). FokI genotype was determined by direct sequencing of all PCR products and performed by Shanghai Sangon Bioengineering Company (partial nucleotide sequences of CC, CT and TT genotypes are shown in Fig. 2).

\section{Diagnosis and staging criteria of renal pathology}

IgAN was diagnosed according to renal pathology. IgAN is characterized by proliferation of mesangial cells, and IgA is dominant or co-dominant in glomerular deposition, which is usually accompanied by complement C3 and varying amounts of IgG and/or IgM (Kiryluk \& Novak 2014).

Renal pathology staging was based on the Oxford classification and crescent scores. Scores were defined as follows: M1, $>50 \%$ of the mesangial area consisting of more than 3 mesangial cells, otherwise scored as M0. E1, narrowed glomerular capillary cavities due to cell proliferation, otherwise scored as E0. S1, any degree of injury in capillary fistula excluding injury to the entire glomerulus or adhesion, otherwise scored as S0. Interstitial fibrosis/tubular atrophy (IFTA) was defined as follows: T0, 0\%-25\%; T1, 26\%-50\%; and T2, $>50 \%$. Crescents were scored as

follows: $\mathrm{C} 0$, no crescent; $\mathrm{C} 1$, crescents in $<25 \%$ of the glomerulus; and $\mathrm{C} 2$, crescents in $\geq 25 \%$ of the glomerulus (Trimarchi et al. 2017). 


\section{Statistical analysis}

119 Statistical analyses were performed using SPSS version 21.0 (SPSS, Chicago, IL, USA). Data 120 with a normal distribution were expressed as mean \pm standard deviation (SD) or percentages.

121 Data with a non-normal distribution were presented as the median and quartile. The chi-squared 122 test was used to determine Hardy-Weinberg equilibrium (HWE). The t-test and chi-squared test 123 were used to determine differences of indicators between two groups. Comparison of clinical 124 indicators among different genotypes was analyzed by variance analysis; distribution of 125 pathological staging among different genotypes was compared by the chi-squared test. Multiple 126 linear regression analysis and binary logistic regression analysis were used to analyze risk factors 127 associated with renal dysfunction in IgAN. $\mathrm{P}<0.05$ was considered to be statistically significant 128 in all analyses.

\section{Results}

130 We enrolled 282 IgAN patients; the sex ratio (male:female) was 1:1.19 (129/153), mean age ( \pm 131 SD) was $33.67 \pm 10.75$ years and 156 patients had renal dysfunction $(55.32 \%)$. There were no 132 significant differences in age and sex between renal dysfunction and control groups. Compared 133 with the control group, SBP, DBP, pulse pressure, BUN, Scr, UA, 24-hour urine protein 134 quantitation (24hUPro) and iPTH levels of the renal dysfunction group were higher, while eGFR, $135 \mathrm{Hb}, 25(\mathrm{OH})_{2} \mathrm{D} 3$ and $25(\mathrm{OH})_{2} \mathrm{D} 2$ were lower $(\mathrm{P}<0.05$ for all $)$. Detailed information is shown in 136 Table 1.

137 Distribution of FokI genotype and allele frequencies was consistent with HWE in enrolled IgAN 138 patients $(\mathrm{P}>0.05$, Table 1). Frequencies of CC, CT and TT genotypes were $19.15 \%, 50.35 \%$ and $13930.50 \%$, and frequencies of $\mathrm{C}$ and $\mathrm{T}$ alleles were $44.33 \%$ and $55.67 \%$, respectively. Frequencies 140 of TT genotype and T allele in the renal dysfunction group were significantly higher than those 141 of the control group $(\mathrm{P}<0.0001)$.

142 Comparison of clinical and pathological indicators between different genotypes is shown in 143 Table 2. There were significant differences in BUN, UA, P, eGFR, 25(OH) $)_{2} \mathrm{D} 3,25(\mathrm{OH})_{2} \mathrm{D} 2$, 144 extent of mesangial cell hyperplasia, capillary intravascular hyperplasia, IFTA and crescents 145 among different genotypes. BUN and $\mathrm{P}$ of $\mathrm{T}$ allele carriers $(\mathrm{TT}+\mathrm{CT})$ were higher than those of 146 non-T allele $(\mathrm{CC})$ carriers, while eGFR, $25(\mathrm{OH})_{2} \mathrm{D} 3$ and $25(\mathrm{OH})_{2} \mathrm{D} 2$ levels of $\mathrm{T}$ allele carriers 
147 were lower than those of non-T allele carriers. Furthermore, proportions of M1, T2 and C2 of T

148 allele carriers were higher than those of non- $\mathrm{T}$ allele carriers $(\mathrm{P}<0.05$ for all).

149 Multiple linear regression analysis showed that eGFR was closely associated with FokI 150 genotypes $(\mathrm{P}<0.05$, Table 3$)$. Additionally, eGFR was also affected by various factors such as 151 age, $\mathrm{BMI}, \mathrm{Hb}, 25(\mathrm{OH})_{2} \mathrm{D} 3$ and pathological stage $(\mathrm{P}<0.05$ for all). Logistic regression analysis

152 showed that TT genotype may be a significant factor of renal dysfunction in IgAN after adjusting 153 for sex, age, $\mathrm{P}, \mathrm{PTH}$ and other factors [odds ratio $(\mathrm{OR})=84.77, \mathrm{P}<0.0001$ ], and the risk of renal 154 dysfunction in TT genotype carriers was 84.77-fold higher than that in CC genotype carriers with 155 IgAN. Furthermore, age $>40$ years $(\mathrm{OR}=9.60, \mathrm{P}=0.005)$, serum $\mathrm{P}(\mathrm{OR}=15.68, \mathrm{P}=0.001)$ and $156 \mathrm{iPTH}(\mathrm{OR}=1.13, \mathrm{P}<0.0001)$ were independent risk factors of renal dysfunction in $\mathrm{IgAN}$ patients. 157 Detailed information is shown in Table 4.

\section{Discussion}

159 IgAN accounts for $40 \%-47.2 \%$ of primary glomerular nephritis in China and is one of the most 160 common primary glomerular diseases worldwide and an important cause of CRF (Wang et al. 161 2015; Wyatt \& Julian 2013). Our results indicated that 55.32\% of IgAN patients have renal dysfunction, which is similar to the proportion of primary IgAN patients with renal failure in India (47\%) (Chowdry et al. 2018). We also found that the $V D R$ gene was closely related to elevated serum iPTH and P, and elevated iPTH and P were independent risk factors for renal dysfunction in IgAN. Similar to our results, studies showed that secondary hyperparathyroidism (SHPT) and hyperphosphatemia not only affect renal progression but also increase the mortality of CKD, especially in ESRD (Ritter \& Slatopolsky 2016). Therefore, the $V D R$ gene may be closely related to renal function and prognosis of IgAN patients. Many studies have confirmed that IgAN has ethnic and regional differences and family aggregation tendencies (Cox et al. 2017; Schena \& Nistor 2018). Genetic causes are important mechanisms of IgAN occurrence and progression. A study from China including 613 IgAN adult

172 patients created the best predictive model of IgAN progression consisting of four loci

173 (rs11150612, rs7634389, rs2412971 and rs2856717). According to the genetic risk score, the risk 174 of disease progression in IgAN patients with moderate and high genetic risk was 2.12- and 3.61175 fold higher than that of IgAN patients with low genetic risk, respectively (Shi et al. 2018). Our 176 study indicated that the frequency of TT genotype in the renal dysfunction group was higher than 
177 that in the control group, and eGFR of T allele carriers was lower than that of non-T allele

178 carriers. Thus, TT genotype is an independent risk factor of renal dysfunction. VDR FokI SNP is

179 closely associated with renal dysfunction in IgAN patients, which also supported the concept that

180 genetic factors play an important role in IgAN renal function and progression. A previous study

181 has shown that VDR FokI polymorphism is associated with risk of CRF in Asians (Li et al. 2018),

182 which is also supported by our findings.

183 The $V D R$ gene is located on the long arm of chromosome 12, with a total length of about $75 \mathrm{~kb}$, 184 and contains 11 exons and several introns. VDR polymorphisms can encode different proteins 185 and cause various physiological effects. Studies have confirmed that VDR polymorphisms affect 186 CKD occurrence and progression such as diabetic nephropathy, lupus nephritis and hypertensive 187 renal damage (Mahto et al. 2018; Yang et al. 2017). Our study also showed that VDR FokI is 188 associated with renal dysfunction in IgAN patients. Renal function of IgAN may be influenced 189 by $V D R$ polymorphisms through the following reasons and mechanisms. First, VDR SNPs affect 190 mRNA quality and stability by interfering with $V D R$ mRNA expression and splicing, 191 subsequently affecting VDR protein number and/or activity, and transactivates VDR protein and 192 target gene(s) (Karonova et al. 2018). Second, VDR polymorphisms may affect CKD occurrence 193 and development such as IgAN by inhibiting the anti-inflammatory activity of active vitamin D, 194 protecting endothelial cells and promoting mesangial cell proliferation, podocyte loss and 195 tubulointerstitial fibrosis (Yang et al. 2012). The FokI locus is located on the transcription 196 initiation site, and SNPs in this region can change the length of the amino acid sequence. When 197 the genotype is $\mathrm{T} / \mathrm{T}$, the initiation codon in $V D R$ is mutated from ATG to ACG, which results in 198 loss of translation function and ultimately changes its biological functions such as proliferation 199 and division (Beysel et al. 2018). This may be one of the potential molecular mechanisms by 200 which FokI TT genotype carriers are more likely to suffer from renal dysfunction in IgAN 201 patients. Ethnic differences in VDR FokI polymorphism and the influence of environmental, 202 geographic, dietary or occupational factors must be further elucidated.

203 Recently, with the development of molecular genetics and the completion of the Human Genome 204 Project, greater attention has been paid to the pathogenesis of genetic factors in IgAN patients. 205 To date, several GWAS have been carried out in IgAN patients of different ancestries, and at 206 least 20 susceptibility loci have been identified, including human leukocyte antigen gene, 
207 complement factor H-related protein genes and tumor necrosis factor superfamily member 13 208 (Han et al. 2016; Yang et al. 2018; Zhu et al. 2015). However, the clinical application value is 209 rarely found. Our study found that VDR gene polymorphism was associated with renal 210 insufficiency of IgAN. Recent studies have shown that active vitamin D and its preparation can 211 significantly alleviate renal dysfunction in CKD patients, reduce proteinuria, inhibit the secretion 212 of parathyroid hormone and delay the progression to end-stage kidney disease and all-cause 213 mortality (Gluba-Brzozka et al. 2018; Melamed et al. 2018). Furthermore, active vitamin D and 214 its preparation are commonly administered to treat CKD-related mineral and bone metabolism 215 (MBD), which improve the prognosis in CKD patients. Active vitamin D is not only an effective 216 therapy for CKD but also a drug that can be safely administered for prolonged periods. As the 217 necessary receptor of active vitamin D, VDR should have significant clinical applying prospects. 218 Our study found serum $\mathrm{P}$ of T allele carriers was higher than that of non-T allele carriers. VDR 219 FokI polymorphism was shown to be associated with MBD (Bouksila et al. 2018). The T (or F) 220 site of FokI protein is three amino acids shorter than the $\mathrm{f}$ (or C) site. Therefore, the affinity for 221 ligand, mRNA stability and transport activity of $\mathrm{F}$ are higher than those of $\mathrm{f}$ (Elias et al. 2018), 222 subsequently increasing intestinal calcium absorption, promoting calcium and phosphorus 223 deposition in bone and affecting serum Ca and P levels. Simultaneously, SHPT can also inhibit 224 phosphate reabsorption in renal proximal tubules. Studies have shown that VDR expression may 225 be affected by calcium homeostasis and adequate calcium intake may offset the influence of 226 227 genetic factors of $V D R$ on bones (Moran et al. 2015). This may explain why we observed no significant difference in calcium levels between different genotypes. Our study also found that 228 $25(\mathrm{OH})_{2} \mathrm{D} 3$ of $\mathrm{T}$ allele carriers was lower than that of non-T allele carriers. Previous studies have 229 shown that $25(\mathrm{OH}) \mathrm{D}$ deficiency is significantly associated with renal pathology severity and increases the risk of kidney progression ( $\mathrm{Li}$ et al. 2016). Thus, the T allele of $V D R$ FokI may be a 231 susceptive allele for renal dysfunction and progression of IgAN.

232 Our study also found that there are different degrees of change in mesangial cell proliferation, 233 capillary proliferation, IFTA and crescent lesions between genotypes; proportions of M1, T2 and 234 C2 of patients with TT genotype were higher than those of non-TT carriers. Several studies have 235 indicated a significant correlation between mesangial hyperplasia, IFTA, crescent and renal 236 dysfunction and progression in IgAN patients (Bao et al. 2014; Xie et al. 2018). Combined with 237 our findings, IgAN patients carrying FokI TT genotype or T allele likely have more serious renal 
238 pathological damage. The loss of VDR can lead to renal fibrosis by affecting perirenal 239 inflammation and epithelial-mesenchymal transition (EMT) (Ito et al. 2013). VDR FokI SNP 240 may influence renal pathology by affecting the quantity or activity of active vitamin D and VDR, 241 which could inhibit EMT, mesangial proliferation and podocyte loss.

242 Several limitations exist in this study. First, the study was a cross-sectional study with small 243 sample size. Thus, we cannot verify the direct causal relationship between FokI polymorphism 244 and renal function. Second, we only evaluated one locus of the $V D R$ gene and did not investigate 245 the influence of inheritance of other VDR SNPs. Finally, the study did not conduct a dietary 246 questionnaire survey and could not exclude potential effects of diet on indicators related to 247 calcium-phosphorus metabolism. Therefore, large-scale cohort studies should be conducted to 248 confirm our findings and explore additional VDR SNPs.

249

250

251

252

253

254

255

256

257

258

259

260

261

262

263

264

265

266

267

268

269

270

271

\section{Conclusions}

IgAN patients have a higher prevalence of renal dysfunction. Patients with the FokI TT genotype are likely to have renal dysfunction, calcium-phosphorus metabolism disorder, mesangial proliferation, IFTA and crescents in IgAN. VDR may be a susceptibility gene for renal dysfunction in IgAN, and VDR SNP is closely related to clinical symptoms and pathological damage in IgAN patients.

\section{Acknowledgments}

We thank Christina Croney, PhD, from Liwen Bianji, Edanz Group China

(www.liwenbianji.cn/ac), for editing a draft of this manuscript.

\section{References}

Bao H, Hu S, Zhang C, Shi S, Qin W, Zeng C, Zen K, and Liu Z. 2014. Inhibition of miRNA-21 prevents fibrogenic activation in podocytes and tubular cells in IgA nephropathy. Biochem Biophys Res Commun 444:455-460. DOI 10.1016/j.bbrc.2014.01.065

Beysel S, Eyerci N, Pinarli FA, Apaydin M, Kizilgul M, Caliskan M, Ozcelik O, Kan S, and Cakal E. 2018. VDR gene Fokl polymorphism as a poor prognostic factor for papillary thyroid cancer. Tumour Biol 40:1010428318811766. DOI 10.1177/1010428318811766

Bouksila M, Kaabachi W, Mrad M, Smaoui W, El Kateb EC, Zouaghi MK, Hamzaoui K, and Bahlous A. 2018. FGF 23, PTH and vitamin D status in end stage renal disease patients affected by VDR Fokl and Bsml variants. Clin Biochem 54:42-50. DOI 10.1016/j.clinbiochem.2018.02.009 
272

273

274

275

276

277

278

279

280

281

282

283

284

285

286

287

288

289

290

291

292

293

294

295

296

297

298

299

300

301

302

303

304

305

306

307

308

309

310

311

312

313

314

315

316

317

318

319

320

321

322

Cho YA, Lee J, Oh JH, Chang HJ, Sohn DK, Shin A, and Kim J. 2018. Vitamin D receptor FokI polymorphism and the risks of colorectal cancer, inflammatory bowel disease, and colorectal adenoma. Sci Rep 8:12899. DOI 10.1038/s41598-018-31244-5

Chowdry AM, Najar MS, Mir MM, Azad H, Rashid RA, Ashraf BM, Ahmed BK, Maqsood WM, and Ahmed WI. 2018. Primary IgA nephropathy in the Kashmiri population. Saudi J Kidney Dis Transpl 29:680-688. DOI 10.4103/1319-2442.235167

Christensen MH, Apalset EM, Nordbo Y, Varhaug JE, Mellgren G, and Lien EA. 2013. 1,25dihydroxyvitamin $D$ and the vitamin $D$ receptor gene polymorphism Apa1 influence bone mineral density in primary hyperparathyroidism. PLoS One 8:e56019. DOI 10.1371/journal.pone.0056019

Cox SN, Pesce F, El-Sayed Moustafa JS, Sallustio F, Serino G, Kkoufou C, Giampetruzzi A, Ancona N, Falchi M, Schena FP, and European Ig ANC. 2017. Multiple rare genetic variants co-segregating with familial IgA nephropathy all act within a single immunerelated network. J Intern Med 281:189-205. DOI 10.1111/joim.12565

Elias RM, Dalboni MA, Coelho ACE, and Moyses RMA. 2018. CKD-MBD: from the Pathogenesis to the Identification and Development of Potential Novel Therapeutic Targets. Curr Osteoporos Rep 16:693-702. DOI 10.1007/s11914-018-0486-0

Gluba-Brzozka A, Franczyk B, Cialkowska-Rysz A, Olszewski R, and Rysz J. 2018. Impact of Vitamin D on the Cardiovascular System in Advanced Chronic Kidney Disease (CKD) and Dialysis Patients. Nutrients 10. DOI 10.3390/nu10060709

Han SS, Yang SH, Choi M, Kim HR, Kim K, Lee S, Moon KC, Kim JY, Lee H, Lee JP, Jung JY, Kim S, Joo KW, Lim CS, Kang SW, Kim YS, and Kim DK. 2016. The Role of TNF Superfamily Member 13 in the Progression of IgA Nephropathy. J Am Soc Nephrol 27:3430-3439. DOI 10.1681/ASN.2015060677

Hu X, Liu M, Ni Y, and Zhang G. 2017. Genetic analysis of the Vitamin D receptor start codon polymorphism (Fokl) in cervical vertebra and lumbar spine pathologies: a meta-analysis. Oncotarget 8:72921-72932. DOI 10.18632/oncotarget.20380

Imam AA, Ibrahim HE, Farghaly MAA, Alkholy UM, Gawish HH, Abdalmonem N, Sherif AM, Ali YF, Hamed ME, Waked NM, Fathy MM, Khalil AM, Noah MA, Hegab MS, Ibrahim BR, Nabil RM, and Fattah LA. 2017. Vitamin D receptor gene Fokl polymorphism in Egyptian children and adolescents with SLE: A case-control study. Lupus 26:1426-1434. DOI 10.1177/0961203317725588

Ito I, Waku T, Aoki M, Abe R, Nagai Y, Watanabe T, Nakajima Y, Ohkido I, Yokoyama K, Miyachi H, Shimizu T, Murayama A, Kishimoto H, Nagasawa K, and Yanagisawa J. 2013. A nonclassical vitamin $D$ receptor pathway suppresses renal fibrosis. J Clin Invest 123:4579-4594. DOI 10.1172/JCI67804

Karonova T, Grineva E, Belyaeva O, Bystrova A, Jude EB, Andreeva A, Kostareva A, and Pludowski P. 2018. Relationship Between Vitamin D Status and Vitamin D Receptor Gene Polymorphisms With Markers of Metabolic Syndrome Among Adults. Front Endocrinol (Lausanne) 9:448. DOI 10.3389/fendo.2018.00448

Kiryluk K, and Novak J. 2014. The genetics and immunobiology of IgA nephropathy. J Clin Invest 124:2325-2332. DOI 10.1172/JCI74475

Levey AS, Tighiouart H, Simon AL, and Inker LA. 2017. Comparing Newer GFR Estimating Equations Using Creatinine and Cystatin $\mathrm{C}$ to the CKD-EPI Equations in Adults. Am J Kidney Dis 70:587-589. DOI 10.1053/j.ajkd.2017.04.012

Li L, Wan Q, Yang S, and Zhao S. 2018. Impact of Vitamin D Receptor Gene Polymorphism on Chronic Renal Failure Susceptibility. Ther Apher Dial. DOI 10.1111/1744-9987.12714

Li M, Foo JN, Wang JQ, Low HQ, Tang XQ, Toh KY, Yin PR, Khor CC, Goh YF, Irwan ID, Xu RC, Andiappan AK, Bei JX, Rotzschke O, Chen MH, Cheng CY, Sun LD, Jiang GR, Wong TY, Lin HL, Aung T, Liao YH, Saw SM, Ye K, Ebstein RP, Chen QK, Shi W, Chew SH, Chen J, Zhang FR, Li SP, Xu G, Tai ES, Wang L, Chen N, Zhang XJ, Zeng YX,

Peer) reviewing PDF | (2019:01:34374:1:1:NEW 20 Apr 2019) 
323

324

325

326

327

328

329

330

331

332

333

334

335

336

337

338

339

340

341

342

343

344

345

346

347

348

349

350

351

352

353

354

355

356

357

358

359

360

361

362

363

364

365

366

367

368

369

370

371

372

373

Zhang H, Liu ZH, Yu XQ, and Liu JJ. 2015. Identification of new susceptibility loci for IgA nephropathy in Han Chinese. Nat Commun 6:7270. DOI 10.1038/ncomms8270

Li XH, Huang XP, Pan L, Wang CY, Qin J, Nong FW, Luo YZ, Wu Y, Huang YM, Peng X, Yang $\mathrm{ZH}$, and Liao $\mathrm{YH}$. 2016. Vitamin D deficiency may predict a poorer outcome of IgA nephropathy. BMC Nephrol 17:164. DOI 10.1186/s12882-016-0378-4

Magistroni R, D'Agati VD, Appel GB, and Kiryluk K. 2015. New developments in the genetics, pathogenesis, and therapy of IgA nephropathy. Kidney Int 88:974-989. DOI 10.1038/ki.2015.252

Mahto H, Tripathy R, Das BK, and Panda AK. 2018. Association between vitamin D receptor polymorphisms and systemic lupus erythematosus in an Indian cohort. Int J Rheum Dis 21:468-476. DOI 10.1111/1756-185X.13245

Melamed ML, Chonchol M, Gutierrez OM, Kalantar-Zadeh K, Kendrick J, Norris K, Scialla JJ, and Thadhani R. 2018. The Role of Vitamin D in CKD Stages 3 to 4: Report of a Scientific Workshop Sponsored by the National Kidney Foundation. Am J Kidney Dis 72:834-845. DOI 10.1053/j.ajkd.2018.06.031

Moran JM, Pedrera-Canal M, Rodriguez-Velasco FJ, Vera V, Lavado-Garcia JM, Fernandez P, and Pedrera-Zamorano JD. 2015. Lack of association of vitamin D receptor Bsml gene polymorphism with bone mineral density in Spanish postmenopausal women. PeerJ 3:e953. DOI 10.7717/peerj.953

Nan YL, Hu YL, Liu ZK, Duan FF, Xu Y, Li S, Li T, Chen DF, and Zeng XY. 2016. Relationships between cell cycle pathway gene polymorphisms and risk of hepatocellular carcinoma. World J Gastroenterol 22:5558-5567. DOI 10.3748/wjg.v22.i24.5558

Prabhakar P, Majumdar V, Kulkarni GB, and Christopher R. 2015. Genetic variants of vitamin D receptor and susceptibility to ischemic stroke. Biochem Biophys Res Commun 456:631636. DOI 10.1016/j.bbrc.2014.12.007

Razi F, Meshkani MA, Zarrabi F, Sadr M, Asgarbeik S, Bandarian F, Forouzanfar K, and Amoli MM. 2019. Haplotypes in vitamin D receptor gene encode risk in diabetic nephropathy. Gene 683:149-152. DOI 10.1016/j.gene.2018.10.017

Ritter CS, and Slatopolsky E. 2016. Phosphate Toxicity in CKD: The Killer among Us. Clin J Am Soc Nephrol 11:1088-1100. DOI 10.2215/CJN.11901115

Saha MK, Julian BA, Novak J, and Rizk DV. 2018. Secondary IgA nephropathy. Kidney Int 94:674-681. DOI 10.1016/j.kint.2018.02.030

Santoro D, Caccamo D, Gagliostro G, lentile R, Benvenga S, Bellinghieri G, and Savica V. 2013. Vitamin D metabolism and activity as well as genetic variants of the vitamin $D$ receptor (VDR) in chronic kidney disease patients. J Nephrol 26:636-644. DOI $10.5301 /$ jn. 5000203

Schena FP, and Nistor I. 2018. Epidemiology of IgA Nephropathy: A Global Perspective. Semin Nephrol 38:435-442. DOI 10.1016/j.semnephrol.2018.05.013

Shi M, Ouyang Y, Yang M, Yang M, Zhang X, Huang W, Wang W, Wang Z, Zhang W, Chen X, Pan X, Ren H, Chen N, and Xie J. 2018. IgA Nephropathy Susceptibility Loci and Disease Progression. Clin J Am Soc Nephrol 13:1330-1338. DOI 10.2215/CJN.13701217

Trimarchi H, Barratt J, Cattran DC, Cook HT, Coppo R, Haas M, Liu ZH, Roberts ISD, Yuzawa Y, Zhang H, Feehally J, Network IIN, Soc RP, and Participants C. 2017. Oxford Classification of IgA nephropathy 2016: an update from the IgA Nephropathy Classification Working Group. Kidney Int 91:1014-1021. DOI 10.1016/j.kint.2017.02.003

Wang N, Bu R, Duan Z, Zhang X, Chen P, Li Z, Wu J, Cai G, and Chen X. 2015. Profiling and initial validation of urinary microRNAs as biomarkers in IgA nephropathy. PeerJ 3:e990. DOI 10.7717/peerj.990

Wyatt RJ, and Julian BA. 2013. IgA nephropathy. N Engl J Med 368:2402-2414. DOI 10.1056/NEJMra1206793

Peer) reviewing PDF | (2019:01:34374:1:1:NEW 20 Apr 2019) 
374

375

376

377

378

379

380

381

382

383

384

385

386

387

388

389

390

391

392

393

394

395
Xie J, Lv J, Wang W, Li G, Liu Z, Chen H, Xu F, Sun J, Ouyang Y, Zhang X, Yang M, Shi M, Zhang W, Ren H, Kiryluk K, Zhang H, and Chen N. 2018. Kidney Failure Risk Prediction Equations in IgA Nephropathy: A Multicenter Risk Assessment Study in Chinese Patients. Am J Kidney Dis 72:371-380. DOI 10.1053/j.ajkd.2018.01.043

Yang B, Zhang J, Liu X, Huang Z, Su Z, Liao Y, and Wang L. 2018. Genetic polymorphisms in HLA-DP and STAT4 are associated with IgA nephropathy in a Southwest Chinese population. Oncotarget 9:7066-7074. DOI 10.18632/oncotarget.23829

Yang L, Ma J, Zhang X, Fan Y, and Wang L. 2012. Protective role of the vitamin D receptor. Cell Immunol 279:160-166. DOI 10.1016/j.cellimm.2012.10.002

Yang L, Wu L, Fan Y, and Ma J. 2017. Vitamin D receptor gene polymorphisms in association with diabetic nephropathy: a systematic review and meta-analysis. BMC Med Genet 18:95. DOI 10.1186/s12881-017-0458-8

Yuzawa Y, Yamamoto R, Takahashi K, Katafuchi R, Tomita M, Fujigaki Y, Kitamura H, Goto M, Yasuda T, Sato M, Urushihara M, Kondo S, Kagami S, Yasuda Y, Komatsu H, Takahara M, Harabuchi Y, Kimura K, and Matsuo S. 2016. Evidence-based clinical practice guidelines for IgA nephropathy 2014. Clin Exp Nephrol 20:511-535. DOI 10.1007/s10157-015-1223-y

Zhu L, Zhai YL, Wang FM, Hou P, Lv JC, Xu DM, Shi SF, Liu LJ, Yu F, Zhao MH, Novak J, Gharavi AG, and Zhang H. 2015. Variants in Complement Factor H and Complement Factor H-Related Protein Genes, CFHR3 and CFHR1, Affect Complement Activation in IgA Nephropathy. J Am Soc Nephrol 26:1195-1204. DOI 10.1681/ASN.2014010096 


\section{Figure 1}

Representative electrophoresis gel of PCR for VDR FokI (rs2228570) polymorphism Lane M: 100-bp marker ladder; Lanes 1-12: PCR products from 12 different DNA samples (292 bp).

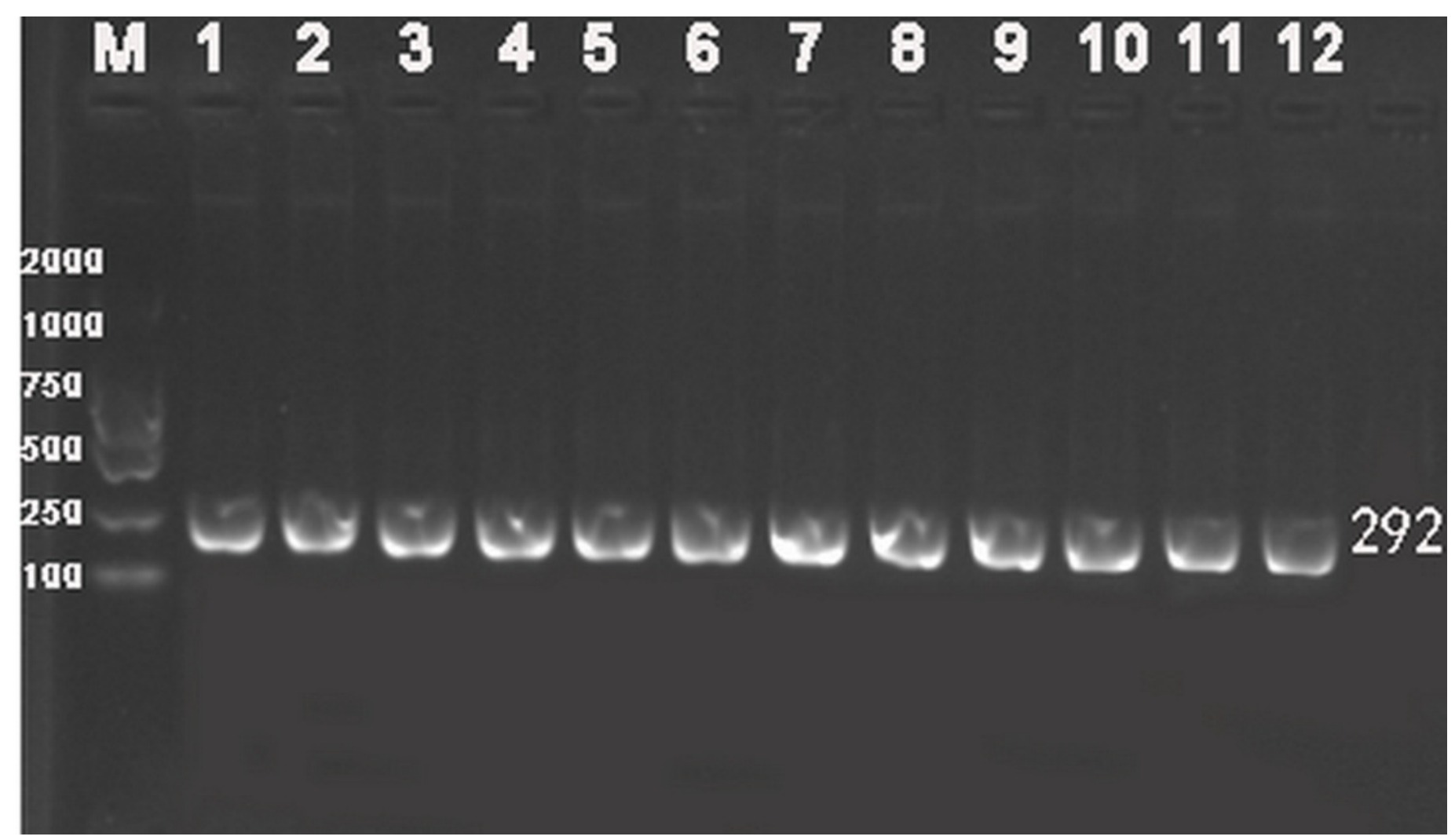


Figure 2

Chromatograms of direct sequencing for VDR Fokl (rs2228570) polymorphism

CC: CC genotype; CT: CT genotype; TT: TT genotype. 


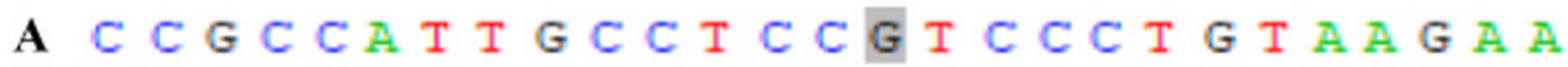
$\uparrow$

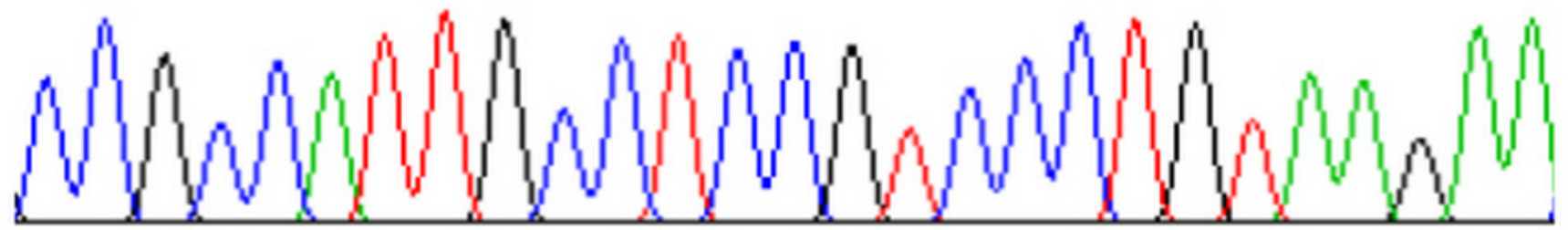

B C C GCCA I I G C C T C C $\underset{\substack{G \\ \text { CT }}}{ }$

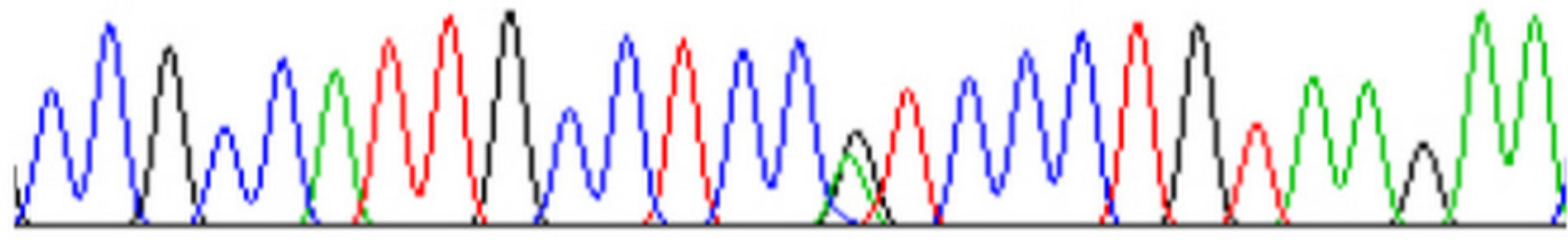

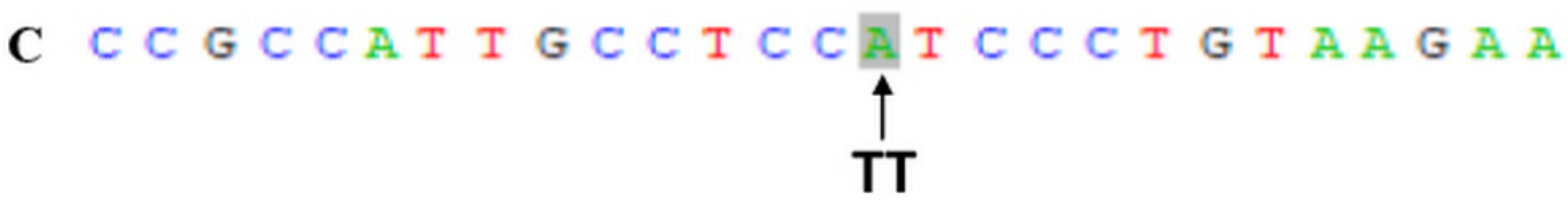

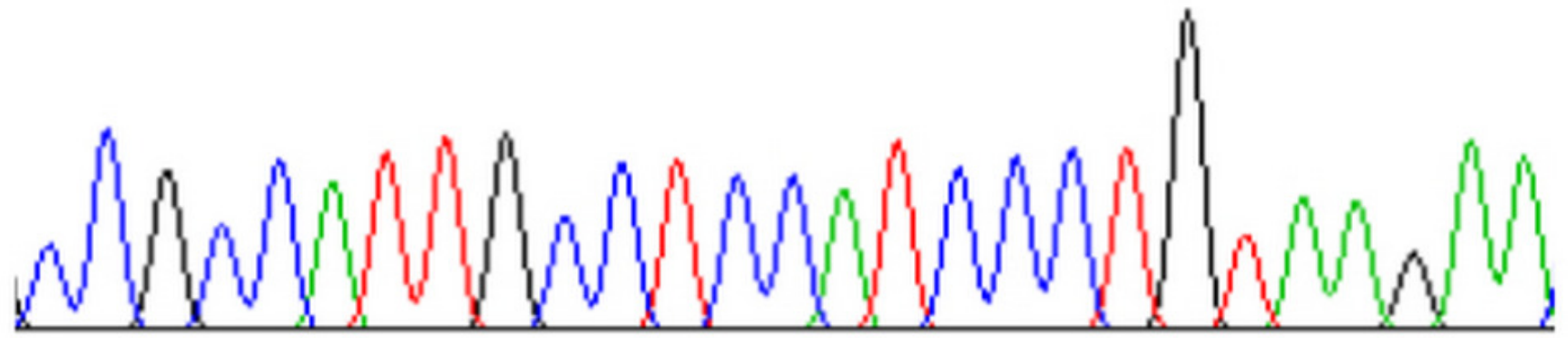




\section{Table $\mathbf{1}$ (on next page)}

Clinical characteristics and genotype and allele frequencies of IgAN patients

25(OH) $)_{2} \mathrm{D} 2$, 25-Dihydroxyvitamin D2; 25(OH) $)_{2} \mathrm{D} 3,25$-Dihydroxyvitamin D3; 24hUpro,

quantitative 24-hour urinary protein; BMI, body mass index; BUN, blood urea nitrogen; $\mathrm{Ca}$, calcium; DBP, diastolic blood pressure; eGFR, estimated glomerular filtration rate; $\mathrm{Hb}$, hemoglobin; iPTH, intact parathyroid hormone; P, phosphorus; SBP, systolic blood pressure; Scr, serum creatinine; UA, uric acid. 
1 Table 1. Clinical characteristics and genotype and allele frequencies of IgAN patients

\begin{tabular}{|c|c|c|c|c|c|}
\hline Parameters & Total & $\begin{array}{l}\text { Renal } \\
\text { dysfunction }\end{array}$ & Control & $t\left(\chi^{2} / Z\right)$ & $p$ \\
\hline Number & 282 & $156(55.32 \%)$ & $126(44.68 \%)$ & & \\
\hline Male/female & $129 / 153$ & $69 / 87$ & $60 / 66$ & 2.406 & 0.121 \\
\hline Age(year) & $33.67 \pm 10.75$ & $34.58 \pm 9.89$ & $32.55 \pm 11.66$ & 1.585 & 0.114 \\
\hline $\operatorname{BMI}\left(\mathrm{kg} / \mathrm{m}^{2}\right)$ & $22.06 \pm 3.39$ & $21.75 \pm 3.42$ & $22.44 \pm 3.32$ & -1.707 & 0.089 \\
\hline SBP(mmHg) & $132.5 \pm 17.97$ & $140.85 \pm 13.89$ & $122.36 \pm 17.20$ & 9.764 & $<0.0001$ \\
\hline $\mathrm{DBP}(\mathrm{mmHg})$ & $81.33 \pm 12.69$ & $86.64 \pm 11.19$ & $74.76 \pm 11.32$ & 8.816 & $<0.0001$ \\
\hline $\begin{array}{l}\text { Pulse } \\
\text { pressure(mmHg) }\end{array}$ & $51.25 \pm 10.92$ & $54.21 \pm 10.56$ & $47.60 \pm 10.28$ & 5.289 & $<0.0001$ \\
\hline $\begin{array}{l}\mathrm{eGFR}(\mathrm{ml} / \mathrm{min} / 1.73 \\
\left.\mathrm{m}^{2}\right)\end{array}$ & $76.49 \pm 35.91$ & $53.63 \pm 21.11$ & $104.79 \pm 29.79$ & -16.260 & $<0.0001$ \\
\hline $\mathrm{Hb}(\mathrm{g} / \mathrm{L})$ & $120.4 \pm 20.58$ & $116.86 \pm 23.46$ & $124.79 \pm 15.30$ & -3.414 & 0.001 \\
\hline $\mathrm{BUN}(\mathrm{mmol} / \mathrm{L})$ & $5.87 \pm 2.46$ & $6.74 \pm 2.76$ & $4.78 \pm 1.41$ & 7.687 & $<0.0001$ \\
\hline $\operatorname{Scr}(\mu \mathrm{mol} / \mathrm{L})$ & $116.2 \pm 99.27$ & $153.2 \pm 120.95$ & $70.50 \pm 13.88$ & 8.476 & $<0.0001$ \\
\hline $\mathrm{UA}(\mu \mathrm{mol} / \mathrm{L})$ & $400.06 \pm 112.81$ & $452.85 \pm 97.83$ & $334.71 \pm 94.66$ & 10.264 & $<0.0001$ \\
\hline $\mathrm{Ca}(\mathrm{mmol} / \mathrm{L})$ & $2.19 \pm 0.14$ & $2.18 \pm 0.13$ & $2.21 \pm 0.16$ & -1.215 & 0.226 \\
\hline
\end{tabular}




\begin{tabular}{llllll}
\hline $\mathrm{P}(\mathrm{mmol} / \mathrm{L})$ & $1.36 \pm 0.48$ & $1.34 \pm 0.39$ & $1.38 \pm 0.58$ & -0.665 & 0.507 \\
$\mathrm{iPTH}(\mathrm{mmol} / \mathrm{L})$ & $51.45(16.26)$ & $55.76(25.72)$ & $41.75(14.67)$ & -6.891 & $<\mathbf{0 . 0 0 0 1}$ \\
$24 \mathrm{hUPro}(\mathrm{g} / \mathrm{d})$ & $1.71 \pm 1.54$ & $2.08 \pm 1.20$ & $1.26 \pm 1.78$ & 4.426 & $<\mathbf{0 . 0 0 0 1}$ \\
& & & & & \\
$25(\mathrm{OH})_{2} \mathrm{D} 3(\mathrm{nmol} / \mathrm{L})$ & $41.89 \pm 19.61$ & $38.91 \pm 18.39$ & $45.68 \pm 20.52$ & -2.759 & $\mathbf{0 . 0 0 6}$ \\
& & & & & \\
$25(\mathrm{OH})_{2} \mathrm{D} 2(\mathrm{nmol} / \mathrm{L})$ & $4.39 \pm 2.04$ & $4.08 \pm 1.93$ & $4.77 \pm 2.12$ & -2.693 & $\mathbf{0 . 0 0 8}$
\end{tabular}

Genotypes

$\mathrm{CC}[\mathrm{n}(\%)] \quad 54(19.15) \quad 15(9.62) \quad 39(30.95)$

$\mathrm{CT}[\mathrm{n}(\%)] \quad$ 142(50.35) $\quad$ 76(48.72) $\quad$ 66(52.38)

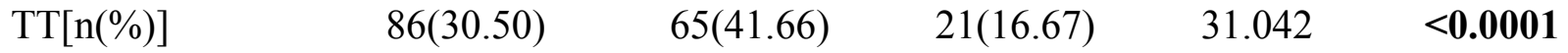

$\begin{array}{lll}\text { Alleles } & H W E(P) & 0.734\end{array}$

$\mathrm{C}[\mathrm{n}(\%)] \quad 250(44.33) \quad 106(33.97) \quad 144(57.14)$

$\begin{array}{llllll}\mathrm{T}[\mathrm{n}(\%)] & 314(55.67) & 206(66.03) & 108(42.86) & 30.322 & <\mathbf{0 . 0 0 0 1}\end{array}$

2 25(OH) $)_{2} \mathrm{D} 2,25$-Dihydroxyvitamin D2; 25(OH) 2 D3, 25-Dihydroxyvitamin D3; 24hUpro,

3 quantitative 24-hour urinary protein; BMI, body mass index; BUN, blood urea nitrogen; Ca,

4 calcium; DBP, diastolic blood pressure; eGFR, estimated glomerular filtration rate; Hb,

5 hemoglobin; iPTH, intact parathyroid hormone; P, phosphorus; SBP, systolic blood pressure; Scr,

6 serum creatinine; UA, uric acid. 


\section{Table 2 (on next page)}

Comparison of clinical and pathological characteristics between IgAN patients by genotypes

25(OH) $)_{2} \mathrm{D} 2$, 25-Dihydroxyvitamin D2; 25(OH) ${ }_{2} \mathrm{D} 3,25$-Dihydroxyvitamin D3; 24hUpro, quantitative 24-hour urinary protein; BUN, blood urea nitrogen; Ca, calcium; DBP, diastolic blood pressure; E, capillary hyperplasia; eGFR, estimated glomerular filtration rate; IFTA, interstitial fibrosis/tubular atrophy; $\mathrm{PTH}$, intact parathyroid hormone; $\mathrm{M}$, mesangial cell proliferation; P, phosphorus; S, segmental glomerular sclerosis; SBP, systolic blood pressure; Scr, serum creatinine; UA, uric acid. 
1 Table 2. Comparison of clinical and pathological characteristics between IgAN patients by

2 genotypes

\begin{tabular}{|c|c|c|c|c|c|}
\hline Parameters & $\mathrm{CC}$ & $\mathrm{CT}$ & TT & $F\left(\chi^{2}\right)$ & $p$ \\
\hline $\mathrm{SBP}(\mathrm{mmHg})$ & $134.22 \pm 22.15$ & $129.23 \pm 17.27$ & $137.09 \pm 15.03$ & 5.579 & 0.004 \\
\hline DBP(mmHg) & $79.78 \pm 12.23$ & $81.71 \pm 13.07$ & $81.69 \pm 12.41$ & 0.500 & 0.607 \\
\hline \multicolumn{6}{|l|}{ Pulse pressure } \\
\hline$(\mathrm{mmHg})$ & $54.44 \pm 11.80$ & $47.52 \pm 9.55$ & $55.41 \pm 10.44$ & 18.958 & $<0.0001$ \\
\hline $\mathrm{BUN}(\mathrm{mmol} / \mathrm{L})$ & $5.50 \pm 2.41$ & $6.31 \pm 2.90$ & $6.20 \pm 2.14$ & 3.343 & 0.037 \\
\hline $\operatorname{Scr}(\mu \mathrm{mol} / \mathrm{L})$ & $100.94 \pm 49.37$ & $111.01 \pm 79.61$ & $134.59 \pm 141.45$ & 2.330 & 0.099 \\
\hline $\mathrm{UA}(\mu \mathrm{mol} / \mathrm{L})$ & $370.44 \pm 100.86$ & $399.88 \pm 132.50$ & $418.97 \pm 75.41$ & 3.115 & 0.046 \\
\hline \multicolumn{6}{|c|}{$\mathrm{eGFR}(\mathrm{ml} / \mathrm{min} / 1.73$} \\
\hline$\left.m^{2}\right)$ & $81.30 \pm 37.37$ & $80.72 \pm 36.13$ & $66.47 \pm 32.87$ & 4.954 & 0.008 \\
\hline 24hUPro(g/d) & $1.59 \pm 1.96$ & $1.81 \pm 1.59$ & $1.61 \pm 1.08$ & 0.697 & 0.499 \\
\hline $\mathrm{Ca}(\mathrm{mmol} / \mathrm{L})$ & $2.16 \pm 0.19$ & $2.20 \pm 0.14$ & $2.21 \pm 0.09$ & 1.879 & 0.155 \\
\hline $\mathrm{P}(\mathrm{mmol} / \mathrm{L})$ & $1.20 \pm 0.32$ & $1.44 \pm 0.54$ & $1.33 \pm 0.44$ & 5.254 & 0.006 \\
\hline iPTH(mmol/L) & $50.73 \pm 15.48$ & $55.40 \pm 28.37$ & $58.16 \pm 18.33$ & 0.763 & 0.468 \\
\hline
\end{tabular}




\begin{tabular}{|c|c|c|c|c|c|}
\hline $25(\mathrm{OH})_{2} \mathrm{D} 3(\mathrm{nmol} / \mathrm{L})$ & $47.88 \pm 8.59$ & $39.88 \pm 21.56$ & $39.61 \pm 22.91$ & 4.187 & 0.016 \\
\hline $25(\mathrm{OH})_{2} \mathrm{D} 2(\mathrm{nmol} / \mathrm{L})$ & $5.02 \pm 0.90$ & $4.17 \pm 2.23$ & $4.16 \pm 2.40$ & 4.380 & 0.014 \\
\hline \multicolumn{6}{|l|}{ M } \\
\hline $\mathrm{M} 0[\mathrm{n}(\%)]$ & $39(72.22)$ & $106(74.65)$ & $36(41.86)$ & & \\
\hline $\mathrm{M} 1[\mathrm{n}(\%)]$ & $15(27.78)$ & $36(25.35)$ & $50(58.14)$ & 26.925 & $<0.0001$ \\
\hline \multicolumn{6}{|l|}{$\mathrm{E}$} \\
\hline $\mathrm{E} 0[\mathrm{n}(\%)]$ & $42(77.78)$ & $136(95.77)$ & $83(96.51)$ & & \\
\hline $\mathrm{E} 1[\mathrm{n}(\%)]$ & $12(22.22)$ & $6(4.23)$ & $3(3.49)$ & 21.198 & $<0.0001$ \\
\hline \multicolumn{6}{|l|}{$\mathrm{S}$} \\
\hline $\mathrm{S} 0[\mathrm{n}(\%)]$ & $24(44.44)$ & $48(33.80)$ & $24(27.91)$ & & \\
\hline $\mathrm{S} 1[\mathrm{n}(\%)]$ & $30(55.56)$ & $94(66.20)$ & $62(72.09)$ & 4.048 & 0.132 \\
\hline \multicolumn{6}{|l|}{ IFTA } \\
\hline $\mathrm{T} 0[\mathrm{n}(\%)]$ & $39(72.22)$ & $69(48.59)$ & $77(89.53)$ & & \\
\hline $\mathrm{T} 1[\mathrm{n}(\%)]$ & $15(27.78)$ & $64(45.07)$ & $6(6.98)$ & & \\
\hline $\mathrm{T} 2[\mathrm{n}(\%)]$ & $0(0)$ & $9(6.34)$ & $3(3.49)$ & 43.907 & $<0.0001$ \\
\hline
\end{tabular}


Crescent

$\mathrm{C} 0[\mathrm{n}(\%)]$

$45(83.33)$

127(89.44)

83(96.51)

C1[n(\%)]

9(16.67)

12(8.45)

$0(0)$

$\mathrm{C} 2[\mathrm{n}(\%)]$

$0(0)$

$3(2.11)$

$3(3.49)$

15.326

0.004

$325(\mathrm{OH})_{2} \mathrm{D} 2,25$-Dihydroxyvitamin D2; 25(OH) 2 D3, 25-Dihydroxyvitamin D3; 24hUpro, 4 quantitative 24-hour urinary protein; BUN, blood urea nitrogen; Ca, calcium; DBP, diastolic 5 blood pressure; E, capillary hyperplasia; eGFR, estimated glomerular filtration rate; IFTA, 6 interstitial fibrosis/tubular atrophy; iPTH, intact parathyroid hormone; M, mesangial cell

7 proliferation; P, phosphorus; S, segmental glomerular sclerosis; SBP, systolic blood pressure; Scr, 8 serum creatinine; UA, uric acid. 


\section{Table 3 (on next page)}

Relationship between eGFR and relative risk factors in IgAN patients

25(OH) 2 D3, 25-Dihydroxyvitamin D3; Alb, albumin; BMI, body mass index; BUN, blood urea nitrogen; DBP, diastolic blood pressure; E, capillary hyperplasia; eGFR, estimated glomerular filtration rate; $\mathrm{Hb}$, hemoglobin; IFTA, interstitial fibrosis/tubular atrophy; $\mathrm{PTH}$, intact parathyroid hormone; $M$, mesangial cell proliferation; $\mathrm{P}$, phosphorus; $\mathrm{S}$, segmental glomerulosclerosis; SBP, systolic blood pressure; UA, uric acid. 
1 Table 3. Relationship between eGFR and relative risk factors in IgAN patients

\begin{tabular}{|c|c|c|c|c|c|c|}
\hline Parameters & Risk factors & B & Std.error & Beta & $t$ & $p$ \\
\hline \multirow[t]{13}{*}{ eGFR } & BUN & -5.108 & 0.011 & -0.423 & -463.547 & $<0.0001$ \\
\hline & SBP & -4.668 & 0.012 & -2.271 & -398.449 & $<0.0001$ \\
\hline & UA & 0.088 & 0.000 & 0.292 & 206.940 & $<0.0001$ \\
\hline & Age $>40$ & 94.215 & 0.180 & 0.885 & 524.790 & $<0.0001$ \\
\hline & BMI & -4.498 & 0.036 & -0.447 & -124.938 & $<0.0001$ \\
\hline & M & 24.518 & 0.073 & 0.369 & 335.974 & $<0.0001$ \\
\hline & $\mathrm{S}$ & -22.264 & 0.072 & -0.277 & -311.333 & $<0.0001$ \\
\hline & Alb & -7.961 & 0.013 & -1.234 & -628.707 & $<0.0001$ \\
\hline & IFTA & 31.241 & 0.146 & 0.542 & 213.292 & $<0.0001$ \\
\hline & $25(\mathrm{OH})_{2} \mathrm{D} 3$ & 1.036 & 0.002 & 0.567 & 483.723 & $<0.0001$ \\
\hline & $\mathrm{P}$ & -58.854 & 0.123 & -0.574 & -480.129 & $<0.0001$ \\
\hline & iPTH & -1.946 & 0.004 & -0.862 & -553.134 & $<0.0001$ \\
\hline & DBP & 5.674 & 0.013 & 1.860 & 439.998 & $<0.0001$ \\
\hline
\end{tabular}




\begin{tabular}{|c|c|c|c|c|c|}
\hline $\mathrm{E}$ & -10.019 & 0.109 & -0.062 & -91.619 & $<0.0001$ \\
\hline $\mathrm{Hb}$ & 0.065 & 0.002 & 0.041 & 38.457 & $<0.0001$ \\
\hline FokI genotypes & 9.469 & 0.067 & 0.181 & 142.337 & $<0.0001$ \\
\hline Crescent & -20.396 & 0.130 & -0.264 & -156.677 & $<0.0001$ \\
\hline $\begin{array}{l}25(\mathrm{OH})_{2} \mathrm{D} 3,25-\mathrm{Dihydroxyvita} \\
\text { nitrogen; DBP, diastolic blood } \\
\text { filtration rate; Hb, hemoglobin } \\
\text { parathyroid hormone; } \mathrm{M} \text {, mesa } \\
\text { glomerulosclerosis; SBP, systo }\end{array}$ & $\begin{array}{l}\text { D3; Alb } \\
\text { ssure; E, } \\
\text { TA, inter } \\
\text { al cell pre } \\
\text { blood pre }\end{array}$ & $\begin{array}{l}\text { bumin; } \\
\text { illary } 1 \\
\text { ial fibr } \\
\text { eration } \\
\text { ire. UA }\end{array}$ & $\begin{array}{l}\text { I, body n } \\
\text { rplasia; e } \\
\text { tubular a } \\
\text { hosphor } \\
\text { c acid. }\end{array}$ & $\begin{array}{l}\text { index; BL } \\
\text { R, estimate } \\
\text { hy; iPTH, } \\
\text { S, segment }\end{array}$ & $\begin{array}{l}\mathrm{J}, \text { blood urea } \\
\text { glomerular } \\
\text { itact }\end{array}$ \\
\hline
\end{tabular}




\section{Table 4 (on next page)}

Analysis of risk factors related to renal dysfunction in IgAN patients

iPTH, intact parathyroid hormone; P, phosphorus. 
1 Table 4. Analysis of risk factors related to renal dysfunction in IgAN patients

Risk factors $\quad$ Renal dysfunction

OR $(95 \% \mathrm{CI}) \quad P$

FokI genotypes

$\mathrm{CC}-1$

CT

$2.79(0.72-10.80)$

0.136

TT

$84.77(13.61-528.01)$

$<\mathbf{0 . 0 0 0 1}$

Age $>40$

$9.60(1.98-46.47)$

0.005

$\mathrm{P}$

$15.68(3.20-76.83)$

0.001

iPTH

$1.13(1.08-1.19)$

$<\mathbf{0 . 0 0 0 1}$

2 iPTH, intact parathyroid hormone; P, phosphorus.

3 